\title{
Drug Traders on a Local Dark Web Marketplace
}

\section{Harviainen, J. Tuomas}

ACM

2020

Harviainen , J T , Haasio , A \& Hämäläinen , L 2020 , Drug Traders on a Local Dark Web Marketplace . in Proceedings of the 23rd International Conference on Academic Mindtrek . ACM , pp. 20-26 , 23rd International Conference on Academic Mindtrek , Tampere , Finland , 29/01/2020 . https://doi.org/10.1145/3377290.3377293

http://hdl.handle.net/10138/312471

https://doi.org/10.1145/3377290.3377293

acceptedVersion

Downloaded from Helda, University of Helsinki institutional repository.

This is an electronic reprint of the original article.

This reprint may differ from the original in pagination and typographic detail.

Please cite the original version. 


\section{Drug Traders on a Local Dark Web Marketplace}

\author{
J. Tuomas Harviainen ${ }^{\dagger}$ \\ Faculty of Information Technology \\ and Communication Sciences \\ Tampere University \\ Tampere Finland \\ tuomas.harviainen@tuni.fi
}

\author{
Ari Haasio \\ Seinäjoki University of Applied \\ Sciences \\ Seinäjoki Finland \\ ari.haasio@seamk.fi
}

\author{
Lasse Hämäläinen \\ Department of Finno-Ugrian and \\ Scandinavian studies \\ University of Helsinki \\ Helsinki Finland \\ lasse.j.hamalainen@helsinki.fi
}

\begin{abstract}
This article uses the concepts of habitus and way of life to analyze cultural and socioeconomic factors related to the lives of drug users who utilize a Finnish dark web site. It draws on a set of 9300 posts on that site, Sipulitori, to understand the way of life of the site's users. The article analyses usernames and forum posts, qualitatively and quantitatively, to find representations of the users' ways of life, and to understand their relationship to drugs. The article finds several different relationships to drugs, as well as the absence of some recognized drug user types on this particular dark web trading site. Drugs appear to be the defining factor of many users' lives, regardless of how actively they are using and how strongly that aspect dominates said lives. The article concludes with a brief discussions on how its findings can be used as basis for future research on such trading forums.
\end{abstract}

\section{KEYWORDS}

Tor network, Drug trading, Drug users, Way of life, Habitus.

\section{Introduction}

This article examines cultural and socioeconomic factors relating to drug trading on the dark web. Following Gehl [21], with 'dark web' we mean parts of the Internet the use of which requires specifically configured browsers or specialized software, such as Tor or I2P. Such parts tend to be pseudo-anonymous and are not usually indexed by search engines such as Google. Nevertheless, they can still be found with specialized search engines (see https://ahmia.fi/ and [31]), and links to particular sites can be found posted on more open Internet sites. The dark web is often associated with criminal activities such as drug trading and the spread of child exploitation images, but it also contains many completely legal commercial activities, as well as human rights groups, democracy networks, contacts between whistleblowers and journalists, and religious communities [21].

J. Tuomas Harviainen, Ari Haasio and Lasse Hämäläinen. 2020. Drug Traders on a Local Dark Web Marketplace. In Proceedings of Academic MindTrek conference 2020. Tampere, Finland, 7 pages.
The article focuses on special traits relating to the way of life and demographic identities of drug users, traits that influence their everyday lives and which are reflected in criminal activities in the Tor network [23]. As its theoretical framework, the article uses Reijo Savolainen's [34, 35] way of life, coming from information seeking studies, and Pierre Bourdieu's [11, 12] concept of habitus. It shows that drug users categorize themselves according to their relationship to the drugs, often also manifest those relationships in the nicknames they use online, and that their information needs and sharing strongly reflect the importance of drugs in their ways of life.

Sipulitori ["Onion marketplace", see Figure 1] is one of the three main Tor network sites that arose within one day, when the Finnish police and customs closed down Sipulikanava, Finland's then main drug trading Tor site, on November 1, 2017. It is the one that has the strongest focus on drugs, while the other two have different purposes (and one of them, Hunajapotta ['Honeychamberpot'], explicitly forbids discussions on narcotics). The drugs in question can be illegal (e.g., narcotics), or legal ones (e.g., hormones, medicine) that are traded without sufficient permits. Like other, more well-known Tor marketplaces (see e.g., [2, 15, 33, 45], and also [3, 13, 16, 37, 40] for critical discussion), the site also hosts other types of traffic (e.g., sales of weapons, prostitution, hacking, and scams). This article is part of a larger project, in which the authors study information practices on the dark web, focusing on Sipulitori. The site is analyzed as a local manifestation of larger dark web phenomena, yet with also some local, unique traits. Its users communicate their sales and purchase intentions on either the forum itself or through Wickr, a popular encrypted instant messenger mobile application compatible with Tor. 


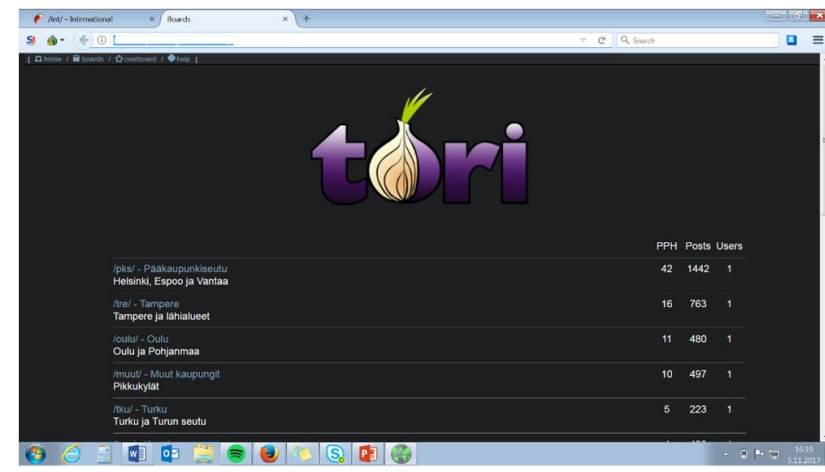

Figure 1. The Sipulitori home page.

This article reviews Sipulitori users' way of life and habitus, based on their posts on the forum. Bourdieu [e.g., 11, 12] describes habitus in different terms in different places, but it is essentially a way of knowing that is embedded in human bodies. It is an internalization of some aspects of one's social world, which in turn influence that individual's behaviour. Habitus provides context for thinking freely about one's possibilities and options, but it also limits what can be seen as possible. As a result, habitus provides options, but also keeps people in place [30]. It is accrued from participation in daily activities and practices, as a kind of byproduct of those activities. Therefore, habitus is not "applicable knowledge" in the traditional sense, but rather what one is. Habitus can thus be understood as a socially and culturally determined system of thinking, perception, norms, and evaluation, internalized by an individual. As a socially and culturally intermediated system of classification, habitus renders a general direction to choices made in everyday life. It does so by indicating which choices are natural or desirable in relation to one's social class or cultural group.[11]

Savolainen $[34,35]$ uses the concept of way of life as the practical application of habitus. It is one's "order of things", based on choices made in everyday life, and reflects prioritizations in e.g., consumption behaviour and hobbies. People prefer to keep things in order, when engaged in everyday life. By observing the way of life, it is possible to understand the decisions and choices people make. In this article, we use forum posts by drug users for that purpose, to see how their information seeking and sharing reflect their everyday lives. Drug users represent a special kind of a subculture, one where drug abuse is a dominant common feature, a feature that unites this group and makes them "others" (e.g., [9]) from the prevailing society's perspective. This affects also their habitus and their way of life.

\section{Method}

The authors collected the material for this article from Sipulitori. Sipulitori is a Finnish Tor network site that is the country's largest drug trading web market, formerly alongside the now defunct cryptomarket Silkkitie (see [33]). The data set consists of 9300 forum posts and responses, collected on a single night as a complete slice of all threads at that time on the site. Sipulitori only preserves the 150 most recent posts (plus responses) on each of its sections. This means that the studied sample contains all of the posts and responses present at that time on the site, from the then existing 22 sections. The sample was taken in January 2018, a few days after New Year. As a result, it may on the one hand contain some irregularities due to the holiday season, but on the other hand, the authors believe it granted also access to certain marketing phenomena (e.g., special, themed offers) not visible during everyday use. The authors furthermore chose to solely use a "lurking" approach to data gathering, as that solves problems related to research ethics on the dark web, such as the researches not identifying themselves, and getting reliable data while not disturbing the practices of the users [18,28].

The posts and responses were copy-pasted into Word documents, with no pictures included. Haasio and Harviainen content analyzed the posts and responses using both quantitative and qualitative methods, treating the process as a form of multiapproach information systems analysis [19]. The messages were placed in four categories (identity, marketing, information needs, information sharing), each of which had 18 subcategories (e.g., "B3: information sharing relating to drug use"). After this, the instant messaging usernames that appeared in the messages were analysed qualitatively, so that hidden meanings behind the name selections on this otherwise anonymous site could be found. Actual messages were searched qualitatively for both explicit and latent meanings, which described the users' lifestyles, habitus, drug trading, and drug use. Central to this process was the analysis of information needs and information sharing that related to control over one's own life (as opposed to just buy/sell statements). These were most frequent on certain sections, including 'Hüümeet' ['Drügs'], a use/effect/discussion area, not used for sales, 'Employment', and 'Everyday life', but appeared here and there on the local threads as well.

For this article, all Wickr usernames that existed in the posts and responses were recorded from the 9300 messages. The total number of usernames perceived from the messages was 1858 . Even though the service itself is anonymous, people send posts containing Wickr usernames, if they want others to contact them. Especially when buying or selling drugs or other goods, the Wickr username is mentioned. We put all of the found usernames into MS Excel, which was used for the quantitative analysis. The usernames were then classified into 17 categories, which were formed by the authors. These categories were:

\section{Gender}

2. Abstract username

3. Place (city, neighborhood etc.)

4. Number

5. Way of life (parties, hippie, etc.)

6. Using/growing/selling/buying drugs

7. Cannabinoids 


\author{
8. Amphetamine \\ 9. LSD \\ 10. Opioids \\ 11. Prescription drugs, hormones \\ 12. Sex, prostitution \\ 13. Fictional character, celebrity \\ 14. Crime \\ 15. Alcohol, cigarettes, snuff \\ 16. Cocaine and ecstasy \\ 17. Other
}

Every username was placed to at least one category. In some cases the username belonged to several categories, e.g., hkisuperman1984. Hki is a shortening of a city (Helsinki), superman is a fictional character and 1984 is number representing likely year when the user was born. In this case the username was placed into categories 3 (=place) 4 (=number) and 13 (=fictional character, celebrity).

After quantitative analysis, a qualitative analysis was conducted. The analysis was based on functional-semantic analysis method, originally created for the study of commercial names by Sjöblom [36] and later adapted to username studies by Hämäläinen $[25,26]$. In this method, usernames are first divided into separate name parts according to the functions of those parts. After that, the name parts are further classified in semantic analysis. The analysis is conducted from the language community's, rather than the name giver's, point of view. This means that we have tried to analyse how an average website user interprets the usernames, instead of contacting name givers in order to interview them about the backgrounds of their names. (For more about the methodology, see $[1,36])$.

The central research question of the part of the project that is described in this article can be summarized as: How do drug users describe their way of life on these local Tor discussions? To answer our question, we have here focused on two examples on how the drug users position themselves to the surrounding world and each other: relationship to drug use, and Wickr usernames.

\section{Hierarchies and Habitus}

A recurring theme on the forum was the way in which people positioned themselves in regards to other groups of drug users. We excluded posts that were expressed solely in very formal, marketing-style language or very simple responses (e.g., just a Wickr id posted in response to a "who wants to buy?" post). Many other messages, however, indirectly or sometimes even directly reflected the users' positions in the loose community. The analysis identified several levels of status, some of which were almost solely observable by their absence.

Most significantly, Sipulitori was used largely by people on the lower income scale of the economic spectrum of drug users. Most of their focus was on heroin replacements, methamphetamine, and cannabinoids. Among the 9300 messages, only a dozen posts about cocaine could be found, and even fewer about heroin (which is quite rare on the Finnish market; [44]). Many of these posts were furthermore critiqued by other users as hoaxes or scams. As a result, the authors deducted that the topmost existing market segment, the rather stereotypical wealthy users of especially cocaine, are largely non-present on the forum. They appear to have their own networks elsewhere. This diverges strongly from findings from larger, more famous drug trading sites like Silk Road, Evolution, and AlphaBay (e.g., [17, 27]). The Wickr nicknames of the users, described further below, also reflected this difference to a significant extent. As noted by Wyatt [46], one of the four key reasons for people not to use certain Internet services is that they do not see those services as useful. In this case, people on the market for cocaine can score their drugs elsewhere, so they likely do not bother with associating with the "lower-class scum" and the extra risks that they create.

The other three key user segments, however, fall into a very different category. They have Tor access, and want to use it. These recreational users, daily users, and at the bottom of the hierarchy, "junkies", all separated themselves from the other demographics. As ways of life, these categories demonstrated the level of control people experienced over their drug use. In some cases, Wickr usernames also reflected this perception: for example, a person with the handle narcinalku ('beginner junkie'), obviously broadcast both inexperience and a desire for heavy drug use. (We could not, however, determine whether the latter factor was ironic or not, only that they wanted to make a purchase.)

The drug user habitus is determined by the amount of time and money spent on keeping up the drug habit. Recreational user posts were made from e.g., skiing resorts, and advertisements recreational buyers were seen especially around Christmas and New Year. Some posters also sought to combine sex and drug use. At the other end of the spectrum could be found people exchanging stolen electronics for small amounts of narcotics, or asking for "any sorts of drugs" to be delivered to a small town. With the lines between buyers and re-sellers also blurring in some of the latter cases, the data furthermore supports a view where a part of the way of life is also the ability to support one's rather high-priced habit and habitus, by selling drugs to also other users. Nevertheless, a clear hierarchy of dependence, and an implicit order of some drugs being considered more high-end than others, could be observed from the posts - and from the Wickr usernames, discussed next.

\section{Usernames}

As noted above, Sipulitori users set up their deals by using Wickr. Wickr users can be connected only by knowing their usernames, so sales advertisements usually include a seller's Wickr username. A typical format we observed was "drug type / advertised quality / transaction safety" - sequence that either 
included the seller's Wickr name, or a request for potential buyers to post theirs (see Figure 2).

\section{Available some really highquality smook. The product is dry well trimmed and covered $w$ resin. More pics etc on wickr..}

\section{You will arrive alone and with money already counted! $18+$ only!!}

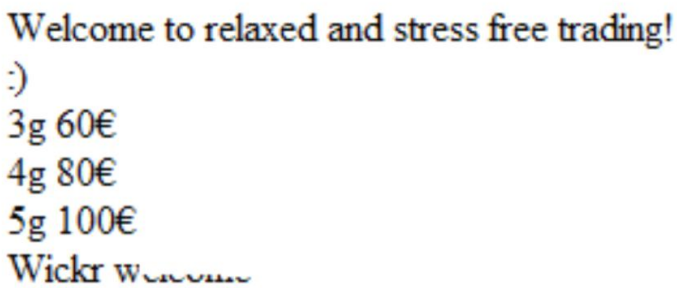

Figure 2. An example post advertising narcotics on Sipulitori, with Wickr username removed. (Translated by Harviainen, with approximations of original typing errors included.)

Trading drugs face-to-face includes risks of violence, robbery, fraud, and police interference. It therefore requires a great level of trust between the buyer and the seller, as well as secrecy (see [21, 22]). However, building this trust can be challenging, especially when the parties do not know each other beforehand (see also [5, $10,14,39])$. A username gives the buyer the first impression of the seller, so it has a great influence on creating and building the trust. Even online, a name is a crucial part of identity, and in the case of self-selected names, often tells something about its owner's personality (e.g., $[4,20])$. They can thus be utilized to examine users' lifestyles.

Information shared in usernames distributed by topics is shown in table 1. Because different kinds of information was sometimes shared in a single username $(n=1858)$, the same username can be classified into several categories. This is why the total percentage is not $100 \%$.

\begin{tabular}{lcc}
\hline Topic & $\begin{array}{c}\text { Mentioned } \\
\text { in } \\
\text { username } \\
(\mathbf{n = 1 8 5 8})\end{array}$ & $\begin{array}{c}\text { \% } \\
(\mathbf{n = 1 8 5 8})\end{array}$ \\
\hline Number & 519 & 27.9 \\
Using/growing/selling/buying & 303 & 16.3 \\
drugs & 268 & 14.4 \\
Gender & 207 & 11.1 \\
Abstract username & 181 & 9.7 \\
Cannabinoids & 154 & 8.3 \\
Way of life (parties, hippie, etc.) & 101 & 5.4 \\
Place (city, neighborhood etc.) & 89 & 4.8 \\
Fictional character, celebrity & 86 & 4.6 \\
Amphetamine & 54 & 2.9 \\
Opioids & 39 & 2.1 \\
Prescription drugs, hormones & 33 & 1.8 \\
Alcohol, cigarettes, snuff & 25 & 1.3 \\
Crime & 15 & 0.8 \\
Sex, prostitution & 9 & 0.5 \\
LSD & 6 & 0.3 \\
Cocaine and ecstasy & 211 & 11.4 \\
Other topic & &
\end{tabular}

Numbers were part of the username in 519 cases (27.9\%). In some cases they referred to using marijuana (pinuplady420) ${ }^{1}$, presumable year of birth (jussu99) and also sometimes to the police code of murder (Teppo187). Remarkably, almost every time the numbers were combined with other information. Abstract usernames were those that could not be interpreted, like $b$ gvffc.

One signal of a user's identity is the choice of language in their name. In the Sipulitori sample, a clear majority of Wickr usernames (57\%) were in Finnish, 20\% in English, 5\% in other languages, and $17 \%$ not in any known language. In some cases, two languages existed in the same username (e.g. annalafamily). The numbers indicate that most users want to present a Finnish rather than an international identity. That could be caused by the prevalent racist attitudes in the Sipulitori community - many users reported that they refuse to do business with people representing certain ethnic backgrounds, because those ethnicities were considered inherently untrustworthy. Some users may therefore want to express that they are native, ethnic Finns. This stands in contrast to international sites like AlphaBay, where nationality could be connected more strongly to locality, and thus also the availability of drugs in an area, instead of ethnicity-related trust [25].

About $25 \%$ of the usernames were connected to drugs. Names referred to dozens of illegal or prescription drugs, but most often to cannabis and amphetamine, which are the most used illegal drugs in Finland [24]. The name did not always refer to the substance that the user is currently selling or buying, but we can assume that the named substance was particularly important to that user. Some names even clearly expressed love or craving for a substance

${ }^{1}$ Names in Finnish translated by authors. 
(oispabentsoja; 'I wish there were benzos', konsertalovee; 'Concerta love', dullamielessä; 'joint on my mind').

References to drugs were mostly made using their unofficial, rather than any official, names. For instance, the data include more than ten different Finnish or English slang words for cannabis (e.g., bud, dank, ganja, kush, kukka 'bud', pilvi 'puff') and seven different Finnish words for amphetamine. Understanding all these references could be challenging, if one is not familiar with drug user slang. Using slang therefore seemed to indicate that the user belongs to the drug user subculture. On the other hand, slang and spoken language expressions were frequently used also in nondrug-related names (e.g., ihateniggaz, lightbringah, rockanrolla). Those names could simply tell that the user has an informal, relaxed attitude - something that is commonly appreciated in the Sipulitori community - as well as being part of masking one's normal communication patterns by slang and typos on drug-related fora [18]. This correlates with the way in which posts that were too correctly written often elicited "hello, cop" -type responses.

According to Haasio, Harviainen and Savolainen [23], there are three types of drug users present on these forums: recreational users, daily users, and "junkies". Users appear acknowledgeable and vocal about which group they belong to. Telling others about one's using habits in a username is one way to identify oneself and classify as a member of one of these groups. This is one of the ways people represent their way of life and relationship to drugs. For example if the user calls himself or herself narkkari00 [junkie00], overdose 5 , or humehiha [drug sleeve], the username is implicating the usage of iv-drugs. In some cases, there was also irony in usernames: mestarinarkkari [masterjunkie] is a good example of this. These users are mainly considered to be junkies, as opposed to the more reliable recreational and daily users. Рajapimu [Skunkbabe] and marinpolttaja420 [potsmoker420], on the other hand, refer to usage on cannabinoids, not hard drugs.

For vendors, the Wickr username can also be an important way to market their product and specify the type of drugs they sell. Examples include aakkoskauppa [alphabetshop ${ }^{2}$ ] and dänäpuoti [skunkshop]. The username may also refer to trust, like rehditkaupat [fairtrade]. The Wickr usernames identify sellers and buyers, which improves the trust between the vendor and the customer. Usernames may also seek to guarantee the quality of drugs for sale. The vendor gets quickly a reputation, if he/she is trustable, and based on what kind of quality his/hers drugs are.

The way of life is represented either by telling something about one's values or habits. The latter was expressed often by describing one's drug usage: how often drugs are used or what kind of drugs one uses. Some usernames contain clear expressions of the way of life like kuositavuosia [usepotforyears]. In many cases also the use of drugs, calling yourself a junkie, or having codes of cannabinoids are also signs of the lifestyle the usernames represent.
Compared to a previous study about usernames in the now defunct cryptomarket AlphaBay [25], the percentage of drugrelated names was relatively low. Usernames that were not related to drugs included a wide range of different themes - for example personal names, place names, fictional characters, and made-up words. However, Sipulitori's Wickr usernames largely lacked the marketing strategies found in the names of AlphaBay drug vendors (ibid.). This confirms the previous finding that most vendors on Finnish online drug market are hobbyists, rather than members of organized crime doing serious business [32].

On a final note on names, people using psychedelics for personal experimentation and "enlightenment", the so-called "psychonauts" [38], were very rare. Only three nicknames were identified indicating that direction. Their posts had little to no discussion on the topic, and showed just normal purchasing behaviour. This too points to Sipulitori being used primarily by people from within only some known segments, not the entire spectrum of Finnish drug users.

\section{Analysis}

Our findings contradict certain earlier studies on drug trading on Tor sites. For example, whereas Barratt, Ferris, and Winstock's [8] subjects thought that using a dark web market granted them easier access to drugs, and access to better quality drugs, the latter factor was not present on Sipulitori. Instead, the study detected a high level of distrust on especially drug quality. This is remarkable for a generally high-trust country like Finland, but in line with what Gehl [21] says about 'proactive paranoia' and operational security having largely replaced political idealism on dark web drug markets after the fall of the original Silk Road.

Feedback on sales was rare, probably emphasized by the fact that Sipulitori does not have a seller rating system. Feedback-giving was nevertheless practiced at times, and many vendors actively solicited feedback. In the spring 2018, Sipulitori administrators founded a separate Tor site called Rottaverkko ['RatNet'] to systematically collect feedback from both drug vendors and buyers. That site did not serve its purpose well, due to the lack and inactivity of users, and was eventually discontinued.

Libertarian thinking, including agorism, in the style of the old Silk Road (see e.g., [21, 27]) was present on Sipulitori, but very rare. The users were far more likely to discuss daily habits or lifecontrol problems than any ideological points about the liberty to trade in what one wants and to use any substance one wants [23]. Without interviews, it is not possible to be certain about the value systems of the site's users, but the absence of such talk on also lifestyle-related forum sections was rather conspicuous.

${ }^{2}$ Aakkoset (alphabets) is a street name for methylenedioxypyrovalerone (MDPV). 
Likewise, unlike earlier research has observed on other sites, Sipulitori's market structure does not allow purchasing "from the comfort of home, eliminating the need to engage with street-based or open-air drug markets" (as per [17]). Instead, it works through advertisements and/or searches, followed by mostly face-to-face trading. While a sell-by-mail section exists on the forum, the great majority of people still conducted their actual trading face to face. This, again, is an area where factors like reputation and ethnicity came in as elements that were used to assess the probable trustworthiness of potential trading partners. This is a topic that requires further research.

The authors, like van Hout and Bingham[41, 42, 43], believe based on the usernames and the posts' contents - that the Sipulitori user base is predominantly male. It uses the Sipulitori site and Wickr to especially reduce the risk of drug trading, but also for the sake of convenience. Due to the site's restrictions, people just do it for convenience to a lesser extent than those on international sites like Silk Road did. While the site does not enable people to always get the narcotics delivered directly to their homes, it gives them a way to organize face-to-face sales without having to look for them through physical travel. From an information-seeking perspective, it enables drug users to utilize active scanning (i.e., following posts made by others) in addition to planned, active information seeking (as per [29]). The active seeking, in turn, is done online, anonymously, instead of by foot or by car. This significantly lowers risks for at least the more experienced users.

The habitus of a generic user is difficult to pin down: sellers differed from seller-buyers, junkies, and recreational users. What nevertheless linked them together was a sense of normalcy in their way of life: they were participating in activities socially sanctioned and supported by the community. That community took care of its own, in not just providing opportunities for trade, but also for peer support. We detected numerous cases of trolling, ridicule and provocation, but also helpful messages on safe drug use, preferred drug effects, and on why for example certain people talking about suicide on the 'Everyday life' section of Sipulitori should not go through with their plans. From our outsider perspective at least, the users' habitus, no matter what their connection to the drugs was, was an in-practice learned way for keeping one's drug-using lifestyle in check, as a functional process in a society that does not condone such practices (see also [6,7] for similar phenomena on other Tor drug sites).

A well-trusted identity is important in selling and buying drugs, and the username functions as one guarantee of that. In some cases, the Wickr username becomes a kind of a brand, which customers know and trust. This is why the usernames are not changed very often. In the discussion forum, traitors ("rats") and their usernames were also sometimes discussed [23]. This demonstrates the importance of Wickr usernames in situations relating to trust.

Most significantly, the study found that drug use and trading dominated the information needs and information sharing of the users to a great extent (see also [23]). Questions and answers about other things (sex, work, money, hobbies) were made from a point of view in which drug use was taken as the established, shared baseline. As noted by Becker [9], diverging from societal values can function as a sub-community building element, as it does here, but also as something that sets people apart from mainstream society. The level of influence drugs have on the way of life of Sipulitori users is remarkable. They form the baseline of everything else on the forum, and are taken for granted. The only real variance is on how, and how often, people on Sipulitori are using drugs, not whether they are.

\section{Conclusion}

This article has discussed the ways in which buyers and sellers of illegal drugs present themselves on a Finnish dark web forum. By looking at users' relationship to drugs, and their usernames, core elements of the users' habitus and way of life can be observed and analyzed. As looking at the users' drug-related discussions on a detailed level is beyond the scope of this article, further research on the topic is certainly needed. The authors hope that with this article, they have shown some key pointers on to which direction should research could go.

In further studies the importance of usernames as a creator of the identity in web should be examined. Likewise, the idea of how one's way of life effects to one's information sharing should be studied more specifically. What kind of information is shared, and what is the part of disinformation or misinformation that is shared? We suspect that the way of life affects strongly also information sharing - does one want to keep it for himself or what are the motives to share information and in which situations? Finally, the question of whether these results are unique to Finnish forums of this type, or actually correlate with e.g., the findings by Demant and Bakken [14] on young drug-related social media users from other Nordic countries, need further work. For example, is the similarity in the discussed drugs related to local preferences, purchasing power, or just drug availability? These questions all require much closer examination in future works.

\section{ACKNOWLEDGMENTS}

This research was partially funded by Academy of Finland grant 329342 (ENNCODE) and Dr. Hämäläinen's personal grant from Alkoholitutkimussäätiö. The authors wish to thank Maria Hakalahti and Reijo Savolainen for their valuable comments during the preparation of this article.

\section{REFERENCES}

[1] Terhi Ainiala, Minna Saarelma and Paula Sjöblom. 2012. Names in Focus. An Introduction to Finnish Onomastics. Finnish Literature Society, Helsinki.

[2] Judith Aldridge and David Décary-Hétu. 2014. Not an 'Ebay for drugs': The cryptomarket 'Silk Road' as a paradigm shifting criminal innovation. SSRN. 
Drug Traders on a Local Dark Web Marketplace

[3] Judith Aldridge and David Décary-Hétu. 2015. A response to Dolliver's "Evaluating drug trafficking on the Tor network: Silk Road 2, the sequel". Int J Drug Policy 26, 11, 1124-1125.

[4] Emilia Aldrin. 2016. Names and identity. In Oxford Handbook of Names and Naming, Carole Hough (Ed.). Oxford University Press, Oxford, 382394.

[5] Silje A. Bakken and Jakob J. Demant. 2019. Sellers' risk perceptions in public and private social media drug markets. Int J Drug Policy, 73 (Nov. 2019), 255-262.

[6] Angus Bancroft. 2017. Responsible use to responsible harm: Illicit drug use and peer harm reduction in a darknet cryptomarket. Health Risk Soc $19,7-8,336-350$

[7] Angus Bancroft and Peter S. Reid. 2016. Concepts of illicit drug quality among darknet market users: Purity, embodied experience, craft and chemical knowledge. Int J Drug Policy 35, (Sept. 2016), 42-49.

[8] Monica J. Barratt, Jason Ferris and Adam R. Winstock. 2014. Use of Silk Road, the online drug marketplace, in the UK, Australia and the USA. Addiction 109, 5, 774-783.

[9] Howard S. Becker. 1963. Outsiders: Studies in the Sociology of Deviance. MacMillan, New York, NY

[10] Ola R. Bilgrei. 2018. Broscience. Creating trust in online drug communities. New Media Soc 20, 8, 2712-2727.

[11] Pierre Bourdieu. 1979. La distinction. Les éditions de Minuit, Paris.

[12] Pierre Bourdieu. 1990. The Logic of Practice. Polity, Cambridge.

[13] Nicolas Christin. 2013. Traveling the Silk Road: A measurement analysis of a large anonymous online marketplace. In Proceedings of the 22nd international conference on World Wide Web, 213-224.

[14] Jakob J. Demant and Silje A, Bakken. 2019. Technology-facilitated drug dealing via social media in the Nordic countries. Background paper commissioned by the EMCDDA for the EU Drug Markets Report 2019.

[15] Diana S. Dolliver. 2015a. Evaluating drug trafficking on the Tor network: Silk Road 2, the sequel. Int J Drug Policy 26, (Nov. 2015) , 1113-1123.

[16] Diana S. Dolliver. 2015b. A rejoinder to authors: Data collection on Tor. Int J Drug Policy, 26 (Nov. 2015), 1128-1129.

[17] Diana S. Dolliver and Jennifer L. Kenney. 2016. Characteristics of drug vendors on the Tor network: A cryptomarket comparison. Vict Offend 11 , 600-620.

[18] Rachael-Heath Ferguson. 2017. Offline 'stranger' and online lurker: methods for an ethnography of illicit transactions on the darknet. Qual Res 17, 6, 683-698.

[19] Robert D. Galliers. 1992. Choosing information systems research approaches. In Information systems research: Issues, methods and practical guidelines, Robert D. Galliers (Ed.). Blackwell Scientific, Oxford, 144-162.

[20] Sarah N. Gatson. 2011. Self-naming practices on the internet: Identity, authenticity, and community. Cult Stud Crit Meth 11, 3, 224-235.

[21] Robert W. Gehl. 2018. Weaving the Dark Web: Legitimacy on Freenet, Tor, and I2P. MIT Press, Cambridge, MA

[22] Aikaterini Grimani, Anna Gavine and Wendy Moncur. 2020. An evidence synthesis of strategies, enablers and barriers for keeping secrets online regarding the procurement and supply of illicit drugs. Int J Drug Policy, 75 .

[23] Ari Haasio, J. Tuomas Harviainen and Reijo Savolainen. 2019 Information needs of drug users on a local dark web marketplace. Information Process Manag, preprint.

[24] Pekka Hakkarainen, Karoliina Karjalainen, Anni Ojajärvi and Mikko Salasuo, M. (2015). Huumausaineiden ja kuntodopingin käyttö ja niitä koskevat mielipiteet Suomessa vuonna 2014. [Drug use, doping and public opinion in Finland: results from the 2014 Drug Survey]. Yhteiskuntapolitiikka, 80, 4, 319-333.

[25] Lasse Hämäläinen. 2019. User names of illegal drug vendors on a darknet cryptomarket. Onoma, 50

[26] Lasse Hämäläinen. 2020. User names in Finnish online communities. Studia Anthroponymica Scandinavica, 35.

[27] Alexia Maddox, Monica J. B arratt, Matthew Allen and Simon Lenton. 2016. Constructive activism in the dark web: cryptomarkets and illicit drugs in the digital 'demimonde'. Inf Comm Soc 19, 1, 111-126.

[28] James Martin and Nicola Christin. 2016. Ethics in cryptomarket research. Int J Drug Policy, 35, (Sept. 2016), 84-91.

[29] Pamela J. McKenzie. 2003. A model of information practices in accounts of everyday life information seeking. J Doc 59, 1 (Feb. 2003), 19-40.

[30] Davide Nicolini. 2012. Practice Theory, Work, \& Organization. Oxford University Press, Oxford.

[31] Juha Nurmi. 2019. Understanding the Usage of Anonymous Onion Services. Ph.D. Dissertation. Tampere University, Tampere, Finland.

[32] Juha Nurmi and Teemu Kaskela, T. 2015. Silkkitie. Päihteiden suomalaista nappikauppaa. [Silkkitie. Finnish minor trade of intoxicants.] Yhteiskuntapolitiikka, 80, 4, 387-394.
Academic MindTrek 2020, January, 2020, Tampere, Finland

[33] Juha Nurmi, Teemu Kaskela, Jussi Perälä and Antti Oksanen. 2017. Seller's reputation and capacity on the illicit drug markets: 11-month study on the Finnish version of the Silk Road. Drug Alcohol Depen 178, (Sept 2017), 201-207.

[34] Reijo Savolainen. 1993. Elämäntapa, elämänhallinta ja tiedonhankinta. Arkielämän ei-ammatillisen tiedon hankinnan tutkimuksen viitekehyksen hahmottelua. [Way of life, mastery of life, and information seeking.] Tampereen yliopisto, Tampere.

[35] Reijo Savolainen. 2008. Everyday Information Practices. A Social Phenomenological Perspective. Scarecrow, Lanham, MD.

[36] Paula Sjöblom. 2006. Toiminimen toimenkuva. Suomalaisten yritysnimien rakenne ja funktiot. [A firm name's job description. The structure and functions of Finnish company names.] Finnish Literature Society, Helsinki.

[37] Kyle Soska and Nicolas Christin. 2015. Measuring the longitudinal evolution of the online anonymous marketplace ecosystem. In USENIX Security Symposium, 33-48.

[38] Johan Söderberg. 2016. DIY research in the psychonaut subculture: A case of unwanted user innovation. In New Production of Users, Sampsa Hyysalo, Torben E. Jensen and Nelly Oudshoorn (Eds.).Routledge, New York, NY, 297-323.

[39] Meropi Tzanetakis, Gerrit Kamphausen, Bernd Wers and Roger von Laufenberg, R. 2016. The transparency paradox. Building trust, resolving disputes and optimising logistics on conventional and online drugs markets. Int J Drug Policy 35, (Sept. 2016), 58-68.

[40] Joe Van Buskirk, Amanda Roxburgh, Sundresan Naicker and Lucinda Burns. 2015. A response to Dolliver's "Evaluating drug trafficking on the Tor network". Int J Drug Policy 26, 11, 1126-1127.

[41] Marie-Claire van Hout and Tim Bingham. 2013a. Silk Road, the virtual drug marketplace: A single case study of user experiences. Int J Drug Policy, 24, 5, 385-391.

[42] Marie-Claire van Hout and Tim Bingham. 2013b. "Surfing the Silk Road": A study of users' experiences. Int J Drug Policy 24, 6, 524-529.

[43] Marie-Claire van Hout and Tim Bingham. 2014. Responsible vendors, intelligent consumers: Silk Road, the online revolution in drug trading. Int J Drug Policy 25, 2, 183-189.

[44] Vili Varjonen. 2015. Huumetilanne Suomessa 2014. [Drug situation in Finland.] Terveyden ja hyvinvoinnin laitos, Helsinki, raportti 1/2015.

[45] Charlotte Walsh. 2011. Drugs, the internet and change. J Psychoactive Drugs 43, 1, 55-63.

[46] Sally Wyatt. 2003. Non-users also matter: The construction of users and non-users of the internet. In How Users Matter. The Co-construction of Users and Technologies, Nelly Oudshoorn and Trevor Pinch (Eds.). MIT Press, Cambridge, MA, 67-81. 